\title{
New evidence on the effectiveness of foreign exchange market intervention
}

\author{
Kees G. Koedijk ${ }^{\text {a }}$, Bruce Mizrach ${ }^{\text {, }}$, Philip A. Stork ${ }^{\mathrm{c}}$, \\ Casper G. de Vries ${ }^{\mathrm{d}, *}$ \\ ${ }^{a}$ Rijksuniversiteit Limburg and LIFE, Maastricht, The Netherlands \\ ${ }^{\mathrm{b}}$ Rutgers University, New Brunswick NJ, USA \\ ${ }^{c}$ Mees Pierson NV, Amsterdam, The Netherlands \\ ${ }^{\mathrm{d}}$ Erasmus Universiteit and Tinbergen Instituut, Oostmaaslaan 950, 3063 DM Rotterdam, The \\ Netherlands
}

\begin{abstract}
This paper compares foreign exchange market intervention in case there is no uncertainty about the extent of an imperfectly sustainable target zone and where there is uncertainty. A well-known example of the first case was the European Monetary System between 1979 and 1992. An example of the latter is the dirty floating of the dollar against the Dmark and yen after the so-called Louvre Accord in 1987. The analysis shows that the instantanenus effectiveness of intervention tends to be larger the more implicit the band policy is. Our empirical results which use Belgian and US intervention data support this claim.
\end{abstract}

Keywords: Official intervention; Imperfect target zones

JEL classification: F31, F33

\footnotetext{
${ }^{+}$Corresponding author. We are grateful to the Belgian central bank and the US Federal Reserve Board for providing us with the intervention data. The fourth author is grateful to Paolo Pesenti for a stimulating discussion. Opinions expressed in this paper are personal and do not necessarily reflect official positions of the Federal Reserve Bank of New York or its Board of Governors.
} 


\section{Analysis}

Concerning the effectiveness of foreign exchange market intervention a vast literature exists; see Almekinders and Eijffinger (1991) for a review. Recently two novel effects of intervention have been detected. The first effect may be termed the anticipation effect. It arises in explicit target zones such as the EMS. As was first explained in Krugman (1991), in anticipation of future intervention when the exchange rate approaches a boundary of the band, the exchange rate movement is already moderated inside the band. The second effect is the signalling effect as first described in Klein (1992). It arises in case of an implicit band when the public is not (fully) informed about the band policy. Intervention may then signal the policy targets. McKinnon (1993) provides a lucid account of the implicit target zone of the Louvre accord.

In this paper we build on the insights from the general intervention and the target zone cum speculative attack literature to study the two effects. The theory indicates that the instantaneous effectiveness of foreign exchange market intervention tends to be larger when there is uncertainty about the width of the semi-fixed band. The crux of the matter is that under an explicit target zone the effects of official intervention partly come before intervention actually takes place, while under the more covert arrangement official intervention has its effect at the time. Therefore, under an explicit arrangement intervention occurs simultaneously with an increase in the realignment probability. Conversely, under a more covert target zone intervention goes hand in hand with a lowering of the immediate 'realignment' probability. Note that this result is not a statement about causality. In the empirical section we test this claim using Belgian and US intervention data. But we first explain the theory in fuller detail. ${ }^{1}$

Following Krugman and Rotemberg (1992), we assume that the monetary authority has only limited funds available to stabilize the fundamental, $f$, which is equal to $v+m$, and thereby to stabilize $s$, the exchange rate. The first part of the fundamental, $v$, follows a random walk and is exogenous, while the second part, $m$, is the policy variable which can be lowered to counteract increases in $v$. For both the implicit and explicit target zone it is assumed that the parities are not entirely fixed; i.e. the amount of reserves is limited. Both regimes are first discussed under the assumption that official intervention is conducted secretly, and at the boundaries (intramarginal intervention is left to the reader). Non-secret intervention is discussed at the close of the section.

The effect of intervention on the exchange rate for the Louvre accord is depicted in Fig. 1. We distinguish two paths for the fundamentals, depending on how $m$ is manipulated. The limited funds, $m$, enable the central bank to keep $f$ at or below $\bar{f}$ until $v+\left(f^{*}-\bar{f}\right)$ reaches the second boundary $f^{*}$. Note that

\footnotetext{
${ }^{1}$ An elaborate version of this paper is available upon request as Koedijk et al. (1994).
} 


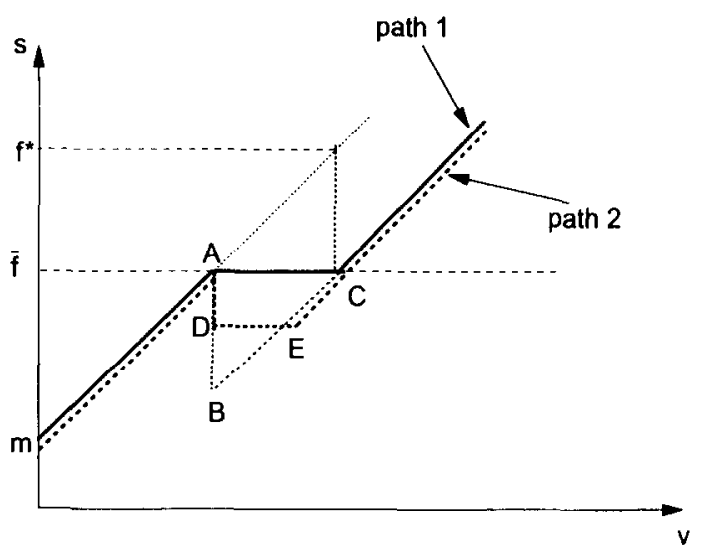

Fig. 1.

$f^{*}-\bar{f}=m$ initially, and this equals the distance AC. Path 1 depicts the situation where the central bank starts to intervene marginally at A when $f$ reaches $\bar{f}$. The intervention keeps $f$ at $\bar{f}$ as $v$ increases further, thereby sliding $f$ along AC. At $\mathrm{C}$ the reserves, $m$, are depleted and $f$ continues to move along the 45 degrees line. An alternative policy would be to intervene discretely at A, thereby lowering $f$ to $\mathrm{D}$, then intervene marginally until $\mathrm{E}$, when the reserves are depleted and $f$ starts to move along the 45 degrees line. This yields path 2 . Also note that any desired point in the triangle $\mathrm{ABC}$ can be crossed by $f$ through manipulation of $m$. The triangle therefore depicts the limits to the intervention policy.

To derive the implied path for the exchange rate, $s$, it is essential to assume that the target for $s$ or $f$, for that matter, is unknown to the public. Therefore, the public does not anticipate future intervention. Hence in case of this dirty float the $s$-path coincides with the $f$-path. Path 1 in Fig. 1 then shows that intervention along AC does not increase the instantaneous probability of $s$ crossing $\dot{f}$. Path 2 demonstrates that the discrete intervention at $\mathrm{A}$ which lowers $s$ and $f$ to $\mathrm{D}$, actually decreases the instantaneous probability of crossing $\bar{f}$.

Now turn to the case of an openly announced target for $s$ as depicted in Fig. 2. The trajectories of $f$ remain as in Fig. 1, but the paths of $s$ do change. (Fig. 2 can overlay Fig. 1) As in Krugman and Rotemberg (1992) we can make a distinction between bounding the fundamentals or bounding the exchange rate, respectively path 1 and path 2 . Note that up to the point where $f$ reaches A, both $s$-trajectories are concave and below the fundamentals path $f$. This conveys the main message of the analysis of fully credible target zones. But while under a fully credible target zone $s$ can always be kept at or below $\bar{s}$, by keeping $f$ at or below $\bar{f}$, this is no longer possible with limited $m$. Keeping $s$ at or below $\bar{s}$, when $f$ reaches A necessitates a discrete intervention $\mathrm{AD}$ and sustained marginal intervention until $\mathrm{E}$ is reached. At E, $m=0$ and the central bank has to give in. Thus bounding $s$ 


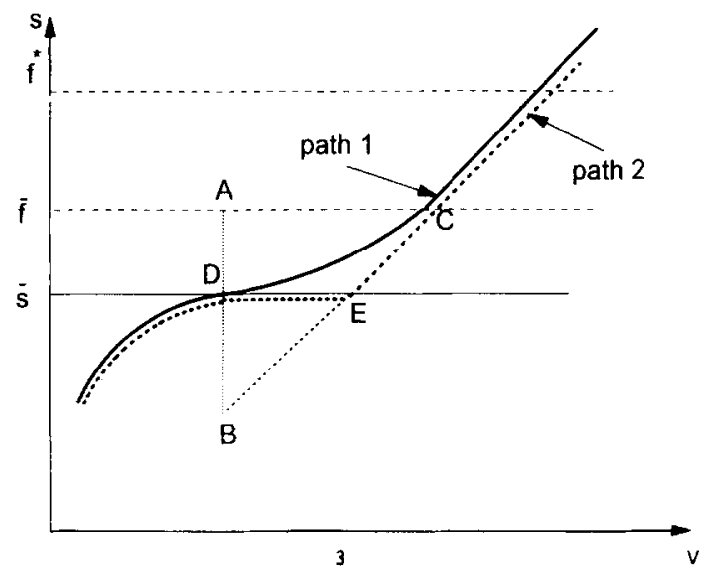

Fig. 2.

yields path 2 . Alternatively we work with a bound on the fundamentals $\bar{f}$. In that case path 1 is relevant. When $f$ attains $\bar{s}$ at point $\mathrm{A}$, the central bank starts to intervene marginally until $\mathrm{C}$ is reached, when $m=0$. The public, being forward looking, anticipates that at $\mathrm{C}$ the funds are zero and realizes that at this point $f=s$ necessarily, otherwise there are possibilities for arbitrage. Thus when $s$ is at $\mathrm{D}$, it has to move towards $\mathrm{C}$ without a jump. This is depicted by path 1 . It follows that a policy of bounded fundamentals leads $s$ to cross $\bar{f}$ immediately. This could be consistent with the fact that within the EMS $s$ often escaped the band before the actual realignment. Further details about the shape of path 1 are derived in the technical appendix of Koedijk et al. (1994). Up to this point the analysis assumed that interventions are done secretly. At times, however, the central Bank openly declares that it is in the market, or the market is able to deduce this indirectly, see Klein (1993). In this case interventions may have a signalling effect as in Klein (1992) and Dominguez and Frankel (1993). Klein (1992) focuses on the case of a perfectly credible zone with public uncertainty about the width of the band. Marginal interventions resolve this uncertainty, and cause a downward jump in the exchange rate. Analogously, in the case of an imperfectly sustainable but secret bandwidth, openly conducted marginal interventions do signal the policy aims and cause the exchange rate to appreciate discretely. Due to the uncertainty about $\bar{f}$ the path of $s$ will be curved, but less so than when the public is informed about $\bar{f}$. In terms of the figures, when $f$ hits $\mathrm{A}, s$ will be somewhere between $\mathrm{A}$ and $\mathrm{D}$. Intervention at $\mathrm{A}$ reveals the target and $s$ jumps down to $\mathrm{D}$, from whereon path 1 in Figure 2 becomes relevant. Nevertheless, the main message of the previous analysis carries over in the case of signalling: Announcing the policy of a target zone, with or without revealing the particulars of the band, leads to discounting the future interventions. This moderates the current exchange rate, but makes future interventions, seemingly, less effective. 
What does this analysis imply in terms of empirical hypotheses? Path 1 policy carries an immediate deceit of the target zone, while under path $2 s$ is just kept at $\bar{s}$, thereby keeping the immediate probability of $s$ turning down constant. Of course, in both Figs. 1 and 2 intervention lowers $m$, thereby decreasing the probability of being able to hold the line in the future. But the fact that the S-shapedness of the $s$-path under the openly announced target zone has moved $s$ already below $f$, has brought forward the effectiveness of future intervention. Thus in Fig. 1 the central bank could move $s$ with a maximum from A to B with a discrete intervention of size $m=\mathrm{AB}$. But in Fig. 2, all resources $m$ would be depleted if the central bank moved $s$ from $\mathrm{D}$ to $\mathrm{B}$, and clearly $\mathrm{DB}<\mathrm{AB}$. This gives the appearance, i.e. no causality is involved, that intervention is less effective or even reversely enhances further depreciation, under a target zone. But the positive effect has been realized before $s$ reaches point $\mathrm{D}$, by the fact that the $s$-path lies below and bends away from the $f$-path.

\section{Empirical results}

In this empirical section, we will use a portfolio-balance model with explicit attention to the specification of expectations' formation in a target zone (see also Svensson (1991)). Central building blocks are the factors influencing realignment risk within the zone. In the following, each of these building blocks is presented.

Consider nominal pure discount bonds maturing at date $t+\tau$. Let $i_{t}^{\tau}$ denote the home currency interest rate and let $i_{t}^{\tau^{*}}$ denote the foreign (German) rate. Define the $\tau$-period interest differential, $\delta_{t}^{\tau}=i_{t}^{\tau}-i_{t}^{\tau^{*}}$. Assuming that uncovered interest parity holds, with $s_{t}$ the spot exchange rate,

$$
\delta_{t}^{\tau} \equiv E_{t}\left[\Delta s_{t+\tau}\right] / \tau \text {. }
$$

Further assume ${ }^{2}$ that there are two possible states for the exchange rate, $j=0,1$, with 1 indicating a devaluation of the target rate, $c_{t}$. Denote the $(\log )$ deviation from the target rate, $x_{t}=s_{t}-c_{t}$, and let $p_{t}^{\tau}$ be the probability of a realignment during the interval $t+\tau$. We can then restate the uncovered interest parity condition as

$$
\delta_{t}^{\tau}=\left(1-p_{t}^{\tau}\right) E_{t}\left[\Delta x_{t+\tau} \mid j=0\right]+p_{t}^{\tau} E_{t}\left[\Delta s_{t+\tau} \mid j=1\right]
$$

by noting that $E_{t}\left[\Delta c_{t+\tau} \mid j=0\right]$ is zero if there is no realignment.

The next step is to specify the two conditional expectations in (2). Following Svensson (1991) we model the first autoregressively,

$$
E_{\imath}\left[\Delta s_{t+\tau} \mid j=0\right]=\beta_{1} x_{\imath} .
$$

\footnotetext{
${ }^{2}$ For a more detailed development of this empirical model of ERM realignments, see Mizrach (1993).
} 
Given an estimate of (3), one can infer, for a given devaluation size $E_{t}\left[\Delta s_{t+\tau} \mid j\right.$ $=1$ ], the probability of a realignment ${ }^{3}$. We also model the size of the jump autoregressively, letting it be proportional to the change in the spot rate during the previous realignment,

$$
E_{t}\left[\Delta s_{t+\tau} \mid j=1\right]=\beta_{2}+\beta_{3} \Delta s_{-1}^{j=1} .
$$

With both expectations identified, we can now assess how credible agents regard the parity.

We assume there is a $m$-vector of state variables, $z_{t}=\left(1, z_{2 \imath}, z_{3 t}, \ldots, z_{m \imath}\right)$, influencing realignment. The first risk factor is the slope of the domestic yield curve. Interest rates help us to isolate the unsterilized portion of intervention. The majority of information seems to lie at the short end of the yield curve, so we chose the three-month, one-month spread, $z_{2 t}=\log \left(1+i_{t}^{3 / 12}\right)-\log \left(1+i_{t}^{1 / 12}\right)$. Edin and Vredin (1993) have also shown that macroeconomic variables are important for realignments. We used the real exchange rate, the nominal money supply, and real output, denoting these as $z_{3 t}, z_{4 t}$ and $z_{5 t}$. A priori, these should effect the probability of realignment as they do in the standard monetary model, $\gamma_{3}<0, \gamma_{4}>0, \gamma_{5}<0$. Let $z_{6 t}$ be intervention by the home country monetary authority. A purchase (sale) of DM is recorded with a positive (negative) sign. If a sale of DM $\left(z_{6}<0\right)$ lowers the probability of devaluation $\left(\Delta p_{t}^{\tau}<0\right)$, this implies $\gamma_{6}$ should be positive. The signalling effects can reinforce or overwhelm the portfolio balance channel. As indicated at the outset, it will be up to the data to distinguish between these hypotheses. To ensure that the probability remains on $[0,1]$, we make a probit transformation, $p_{t}=\varphi\left(\gamma z_{t}\right)$, leading to the econometric specification

$$
\delta_{t}^{\tau}=\left[\beta_{1}\left(1-\varphi\left(\gamma z_{t}\right)\right) x_{t}+\beta_{2} \varphi\left(\gamma z_{t}\right)+\beta_{3} \varphi\left(\gamma z_{t}\right) \Delta s_{-1}^{k=1}\right] / \tau .
$$

Koedijk et al. (1993) obtained data from the Bank of Belgium on their intervention activity which we utilize here. The Belgian data are indicator variables, with +1 indicating that the central bank was in the market. To identify DM sales, we assumed that any intervention in the weak $0.025 \%$ of the band was a sale of DM to support the Franc. The U.S. data are released to the public after some delay and were provided to us by the Board of Governors. Interventions are actual amounts (in millions of US dollars or DM) of intervention both in the market and directly with the customer. We used a 22-day moving sum of both intervention series in the empirical work. Because the dollar had no explicit target, we use a one-month moving average of the spot rate as the zone of stabilization. The exchange rate data are nominal ecu exchange rates converted into DM terms. The interest rates are annualized one- and three-month, Euromarket rates, $i_{t}^{1 / 12}$, and $i_{t}^{3 / 12}$, with the

\footnotetext{
${ }^{3}$ This 'drift adjustment' of interest differentials for the expected depreciation within the band was pioneered by Bertola and Svensson (1993).
} 
Table 1

Results for target switching model ${ }^{\mathrm{a}}$

\begin{tabular}{|c|c|c|c|c|c|c|c|c|c|c|}
\hline \multirow[t]{3}{*}{ Curr } & \multicolumn{3}{|c|}{ Expectations } & \multicolumn{7}{|l|}{ Probit } \\
\hline & $\begin{array}{l}\text { In } \\
\text { band }\end{array}$ & Cons. & Jump & Cons. & $\begin{array}{l}\text { Term } \\
\text { str. }\end{array}$ & $\begin{array}{l}\text { Real } \\
\text { FX }\end{array}$ & $\mathbf{M}$ & Outpt & Intervent & $\bar{R}^{2}$ \\
\hline & $\beta_{1}$ & $\beta_{2}$ & $\beta_{3}$ & $\gamma_{1}$ & $\gamma_{2}$ & $\gamma_{3}$ & $\gamma_{4}$ & $\gamma_{5}$ & $\gamma_{6} \times 10^{-9}$ & \\
\hline BF & $\begin{array}{r}0.014 \\
(0.78)\end{array}$ & $\begin{array}{r}0.016 \\
(16.39)\end{array}$ & & $\begin{array}{l}-0.954 \\
(14.14)\end{array}$ & $\begin{array}{r}-34.750 \\
(4.07)\end{array}$ & $\begin{array}{r}-2.782 \\
(1.28)\end{array}$ & $\begin{array}{r}-4.262 \\
(1.50)\end{array}$ & $\begin{array}{r}-0.306 \\
(0.85)\end{array}$ & $\begin{array}{r}-10.818 \\
(3.77)\end{array}$ & 0.16 \\
\hline US\$ & $\begin{array}{c}-0.036 \\
(5.72)\end{array}$ & & $\begin{array}{r}0.028 \\
(24.57)\end{array}$ & $\begin{array}{r}2.495 \\
(3.76)\end{array}$ & $\begin{array}{c}68.884 \\
(0.79)\end{array}$ & $\begin{array}{r}1.293 \\
(0.30)\end{array}$ & $\begin{array}{r}-153.148 \\
(2.79)\end{array}$ & $\begin{array}{l}94.240 \\
(2.15)\end{array}$ & $\begin{array}{r}0.803 \\
(3.92)\end{array}$ & 0.52 \\
\hline
\end{tabular}

Nonlinear least squares estimation of (5) with HAC $t$-statistic in parentheses.

German rates bearing an asterisk. For the dependent variable in (5), we set, $\delta_{t}^{1 / 12}=\log \left(1+i_{t}^{1 / 12}\right)-\log \left(1+i_{t}^{1 / 12^{*}}\right)$.

We consider the realignment risk in a 22 -day period (one month in daily data), $p_{t}^{1 / 12}$. The real exchange rate is the spot rate times the ratio of the German to the home country consumer price levels. We use an M2 equivalent for the money supplies and industrial production as the output series. To transform these data to a daily frequency, we interpolate from monthly series. Because of the induced autocorrelation, we take differences, and lag the series by one month. ${ }^{4}$

$$
\delta_{t}^{1 / 12}=\log \left(1+i_{t}^{1 / 12}\right)-\log \left(1+i_{t}^{1 / 12^{*}}\right) .
$$

The estimation sample for Belgium runs from the inception of the ERM in March 1979 to July of 1991 where our intervention data end. For the dollar, we focus on the period after the February 1987 Louvre accord of the G-7 countries. This is a period of active intervention by the Federal Reserve which essentially ends in October of 1989 , so we stop our U.S. sample there.

Results of the regression (5) are in Table 1. There is a clear distinction between the semi-fixed exchange rate and flexible exchange rate results. For the Belgian Franc, the effect of central bank intervention is clearly dominated by signalling. The estimates of $\gamma_{6}$ imply that one day's intervention increases the probability of realignment, on average, about $2.2 \%$ for the Belgian Franc. For the U.S. instead, the estimates imply that a one hundred million dollar intervention lowers the probability of realignment by $3.2 \%$.

To summarize, in this paper we compare the relative effectiveness of foreign exchange market intervention in exchange rate systems where there is no uncertainty about the width of the target zone and when there is uncertainty. A

\footnotetext{
${ }^{4}$ All the data will share this autocorrelated component because of the month-long overlapping expectations in the data. We will use heteroscedasticity and autocorrelation consistent estimates to correct the standard errors.
} 
well-known example of the first is the exchange rate mechanism (ERM) of the European Monetary System. An example of the latter is the dirty float of the dollar against the Deutschemark and the yen after the so-called Louvre accord of 1987. Our theoretical analysis implies that the benefits of intervention are realized sooner in a target zone, well before the exchange rate reaches its fluctuation limit. If intervention comes at the weak edge of the band, it signals weakness to the market and may even help to undermine the currency. When there is uncertainty about the width of the band, intervention is likely to be more effective. Our empirical results with Belgian and U.S. intervention data support this claim.

\section{References}

Almekinders, G.J. and S.C.W. Eijffinger, 1991, Empirical evidence on foreign exchange market intervention: Where do we stand?, Weltwirtschaftliches Archiv, 645-677.

Bertola, G. and L.E.O. Svensson, 1993, Stochastic devaluation risk and the empirical fit of target zone models, Review of Economic Studies 60, 689-712.

Dominguez, K.M. and J.A. Frankel, 1993, Does foreign exchange intervention matter? The portfolio effect, American Economic Review 83, 1356-1369.

Edin, P. and A. Vredin, 1993, Devaluation risk in target zones: Evidence from the Nordic countries, Economic Journal 103, 161-175.

Klein, M., 1992, Big effects of small interventions: The informational role of intervention in exchange rate policy, European Economic Review 36, 915-924.

Klein, M.W., 1993, The accuracy of reports of foreign exchange intervention, Journal of International Money and Finance 12, 644-653.

Koedijk, K.G., P.A. Stork and C.G. de Vries, 1993, Between realignments and intervention, Working paper TI 93-192.

Koedijk, K.G., B. Mizrach, P.A. Stork and C.G. de Vries, 1994, New evidence on the effectiveness of foreign exchange market intervention, Working paper WP 94-20 (LIFE, Maastricht).

Krugman, P., 1991, Target zones and exchange rate dynamics, Quarterly Journal of Economics 56, $669-682$.

Krugman, P. and J. Rotemberg, 1992, Speculative attacks on target zones, in: P. Krugman and M. Miller, eds., Exchange rate targets and currency bands (Cambridge University Press, Cambridge).

McKinnon R.I., 1993, The rules of the game: International money from a historical perspective, Journal of Economic Literature 31, 1-44.

Svensson, L.E.O., 1991, The term structure of interest rate differentials in a target zone: Theory and Swedish data, Journal of Monetary Economics 28, 87-116. 